IRA-International Journal of Education \& Multidisciplinary Studies

ISSN 2455-2526; Vol.04, Issue 02 (2016)

Pg. no. 309-316

Institute of Research Advances

http://research-advances.org/index.php/IJEMS

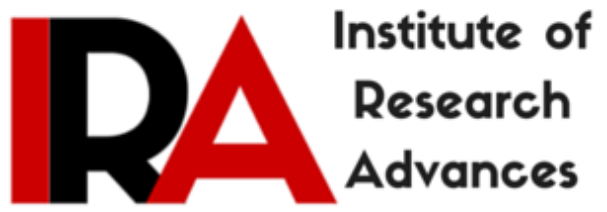

\title{
A Comparative Study of Perception of Secondary School Teachers in Relation to Quality Assurance of Curricular Programme of Different Educational Boards
}

\author{
Mitesh Gala \\ Research Scholar, \\ Nagpur University, Maharashtra, India.
}

Type of Review: Peer Reviewed

DOI: http://dx.doi.org/10.21013/jems.v4.n2.p9

\section{How to cite this paper:}

Gala, M. (2016). A Comparative Study of Perception of Secondary School Teachers in Relation to Quality Assurance of Curricular Programme of Different Educational Boards. IRA International Journal of Education and Multidisciplinary Studies (ISSN 2455-2526), 4(2), 309-316. doi:http://dx.doi.org/10.21013/jems.v4.n2.p9

(C) Institute of Research Advances

\section{(cc) EY-NC}

This work is licensed under a Creative Commons Attribution-Non Commercial 4.0 International License subject to proper citation to the publication source of the work.

Disclaimer: The scholarly papers as reviewed and published by the Institute of Research Advances (IRA) are the views and opinions of their respective authors and are not the views or opinions of the IRA. The IRA disclaims of any harm or loss caused due to the published content to any party. 


\section{"Quality is the most significant paradigm of this century and as vital to an organization's present and future health."}

〜Covey (1993)

The quality assurance of secondary education helps secondary school students realize their full human potential and helps them take appropriate place in society as productive, responsible and democratic citizens. In the present day, in national and international perspectives, quality is the top of most agenda. Quality of education has significant impact and invaluable contribution to the area of development.

Education and academic quality can mean different things to different people, depending on their perspective, role and context and, in part because of this, quality is notoriously difficult to evaluate. The question of how to do this has been pursued for many years. Nevertheless, the goal of improving educational quality is agreed by all and stimulated further by educationist across the world.

(Kothari Commission, 1966) looked at the school curriculum as blend of learning experiences provided under supervised conditions. It also emphasized on the inclusion of work experience in the school education to suit the age and maturity level of the students. The following key areas were identified by the commission.

$\checkmark \quad$ Free and Compulsory Education

$\checkmark$ Status, Emoluments and Education of Teachers

$\checkmark$ Development of languages - Three Language formula

$\checkmark$ Equalization of Educational opportunities

$\checkmark$ Identification of talent

$\checkmark$ Work experience and National Service

$\checkmark$ Science Education and Research

$\checkmark$ Education for agriculture and industry

$\checkmark$ Production of books

$\checkmark$ Games and Sports

$\checkmark$ Education of minorities

The commission broadly recommended focusing on the above key areas to uplift the education system of India.

(UNICEF, June 2000) : A paper presented by UNICEF at the meeting of The International Working Group on Education Florence, Italy studied the Quality Outcomes in school education on the basis of learning environments, processes, content, students and teachers as learners.

(Leung, 2001) in his study stated that principals and school teachers in majority school found the quality as an important aspect in majority schools, but accepting the workload was a major hurdle for most of the teacher.

(School Council of India, 2007) found that all the educational boards of secondary education gave high importance to the evaluation and the examination system to enhance the quality of their educational programmes. 
(Khaled Almadani, 2011) opined that the whole educational system shall focus on learner and must work on understanding rather than memorization, group project, restoring visual spatial aspects of learning, rethinking on a balanced curriculum, reworking on the national examination systems to improvise the quality of school education.

(Hislop, May 2012) has recommended strongly the collaboration of all the stake holders is must to achieve the vision of high quality education services for young people i.e students.

(Vakharia, February 2012) found a significant relationship between AQ and self esteem of secondary school students on the basis gender for male students and on the basis of school type.

(Balani, 2015) found positive and significant relationship between all the managerial functions and overall managerial functions performed by school principals which affects school effectiveness positively and significantly. He concluded that school principals play a significant role in creating the school effectiveness. One more outcome of the study suggests that principals of CBSE schools have shown significant impact than principals of SSC board schools.

All these comprehensive reviews of the study have helped the researcher to identify the gaps in the contemporary educational research carried out by the experts across the globe. The researcher is teaching in one of the leading schools of South Mumbai and was desirous to know more about the quality assurance of the educational programmes offered by the secondary school of different educational boards. Hence the researcher was motivated to frame the following aim of the study to pursue his study as follows:

Aim of the study: A comparative study of perception of secondary school teachers in relation to quality assurance of curricular programme of different educational boards.

\section{Objectives of the study:}

1. To study the perception of secondary school teachers in relation to quality assurance of curricular programme of secondary schools of different educational boards.

2. To compare the perception of secondary school teachers in relation to quality assurance of curricular programme of secondary schools with respect to

a. Academic Achievement

b. Democratic Environment

c. Mode of Evaluation

d. Professional Competence

e. Teaching Learning Process

of different educational boards.

\section{Hypothesis of the study:}

1. There is no significant difference in the perception of secondary school teachers in relation to quality assurance of the components of curricular programme of secondary schools of different educational boards, namely:
i. ICSE
ii. CBSE
iii. SSC 


\section{iv. IGCSE.}

2. There is no significant difference in perception of secondary school teachers in relation to quality assurance of the curricular programmes of secondary schools with respect to
a. Academic Achievement
b. Democratic Environment
c. Mode of Evaluation
d. Professional Competence
e. Teaching Learning Process of different educational boards.

Scope and Limitations of the Study: This study covers the perceptions of secondary school teachers in relation to the quality assurance of curricular programme of different educational boards. The study includes collection of data from CBSE, ICSE, SSC and IGCSE board schools of Mumbai. The study is carried out in Mumbai Jurisdiction only. The study includes only English medium schools. The data collected will be collected from the secondary school teachers of CBSE, ICSE, SSC and IGCSE boards.

Delimitations of the Study: This study compares Academic Achievement, Democratic Environment, Mode of Evaluation, Professional Competence \& Teaching Learning Process, the components of the curricular programme of secondary schools. The study does not include any other city, than Mumbai. The study does not include vernacular medium school teachers. The study does not include the Open schooling systems in India.

Research Design: The descriptive survey research method is used for the present study. The perceptions of 278 teachers of SSC, 61 teachers of IGCSE, 322 teachers of ICSE and 260 teachers of CBSE was studied in relation to quality assurance of curricular programme.. The rating scale was prepared to measure the quality assurance due to educational programmes under different boards i.e. CBSE, ICSE, SSC and IGCSE. The tool comprised 20 items; these items were presented in the form of questionnaire. The tool was validated and standardized with the help of experts. The cronbach's alpha was calculated to measures the internal consistency of the quality of the prepared rating scale. The cronbach's alpha was 0.896 . The systematic stratified multi stage random technique was used for the collection of the data. The data was analyzed by carrying out the descriptive and inferential analysis. The measure of central tendency and measure of variability were computed for the purpose of descriptive data analysis and ANOVA and t-test were computed to test the hypothesis of the study.

\section{Findings of the study:}

The quality assurance of Curricular Programme of different educational school boards on the basis of various components is as follows:

$\checkmark$ The mean score of Academic Achievement, the component of Curricular Programme is the highest of IGCSE school board and lowest of SSC school board.

$\checkmark$ The mean score of Democratic Environment, the component of Curricular Programme is the highest of IGCSE school board and lowest of SSC school board.

$\checkmark$ The mean score of Mode of Evaluation, the component of Curricular Programme is the highest of IGCSE school board and lowest of SSC school board.

$\checkmark$ The mean score of Professional Competence, the component of Curricular Programme is the highest of IGCSE school board and lowest of SSC school board. 
$\checkmark$ The mean score of Teaching and Learning process, the component of Curricular Programme is the highest of IGCSE school board and lowest of SSC school board.

\section{Quality assurance of Academic Achievement, the component of Curricular Programme:}

There is a significant difference in the quality assurance of Academic Achievement, the component of Curricular Programme among secondary schools of different boards of Mumbai district. Since F value was found to be significant, each pair of means was then subjected to t-test and the following results were determined among the different pair of means.

$\checkmark$ The quality assurance of academic achievement, the component of curricular programmes of CBSE school boards is better than ICSE board schools.

$\checkmark$ The quality assurance of academic achievement, the component of curricular programmes of ICSE school boards is better than SSC board schools.

$\checkmark$ The quality assurance of academic achievement, the component of curricular programmes of IGCSE school boards is better than ICSE board schools.

$\checkmark$ The quality assurance of academic achievement, the component of curricular programmes of CBSE school boards is better than SSC board schools.

$\checkmark$ The quality assurance of academic achievement, the component of curricular programmes of CBSE and IGCSE school boards is same.

$\checkmark$ The quality assurance of academic achievement, the component of curricular programmes of IGCSE school boards is better than SSC board schools.

Quality assurance of Democratic Environment, the component of Curricular Programme:

There is a significant difference in the quality assurance of Democratic Environment, the component of Curricular Programme among secondary schools of different boards of Mumbai district. Since F value was found to be significant, each pair of means was then subjected to t-test and the following results were determined among the different pair of means.

$\checkmark$ The quality assurance of Democratic Environment, the component of curricular programmes of ICSE school boards is better than CBSE board schools.

$\checkmark$ The quality assurance of Democratic Environment, the component of curricular programmes of ICSE school boards is better than SSC board schools.

$\checkmark$ The quality assurance of Democratic Environment, the component of curricular programmes of ICSE and IGCSE school boards is same.

$\checkmark$ The quality assurance of Democratic Environment, the component of curricular programmes of CBSE school boards is better than SSC board schools.

$\checkmark$ The quality assurance of Democratic Environment, the component of curricular programmes of IGCSE school boards is better than CBSE board schools.

$\checkmark$ The quality assurance of Democratic Environment, the component of curricular programmes of IGCSE school boards is better than SSC board schools. 


\section{Quality assurance of Mode of Evaluation, the component of Curricular Programme}

There is a significant difference in the quality assurance of Mode of Evaluation, the component of Curricular Programme among secondary schools of different boards of Mumbai district. Since F value was found to be significant, each pair of means was then subjected to t-test and the following results were determined among the different pair of means.

$\checkmark$ The quality assurance of Mode of Evaluation, the component of curricular programmes of CBSE school boards is better than ICSE board schools.

$\checkmark$ The quality assurance of Mode of Evaluation, the component of curricular programmes of ICSE school boards is better than SSC board schools.

$\checkmark$ The quality assurance of Mode of Evaluation, the component of curricular programmes of IGCSE school boards is better than ICSE board schools.

$\checkmark$ The quality assurance of Mode of Evaluation, the component of curricular programmes of CBSE school boards is better than SSC board schools.

$\checkmark$ The quality assurance of Mode of Evaluation, the component of curricular programmes of CBSE and IGCSE school boards is same.

$\checkmark$ The quality assurance of Mode of Evaluation, the component of curricular programmes of IGCSE school boards is better than SSC board schools.

Quality assurance of Professional Competence, the component of Curricular Programme

There is a significant difference in the quality assurance of Professional Competence, the component of Curricular Programme among secondary schools of different boards of Mumbai district. Since F value was found to be significant, each pair of means was then subjected to t-test and the following results were determined among the different pair of means.

$\checkmark$ The quality assurance of Professional Competence, the component of curricular programmes of CBSE school boards is better than ICSE board schools.

$\checkmark$ The quality assurance of professional competence, the component of curricular programmes of ICSE and SSC school boards is same.

$\checkmark$ The quality assurance of Professional Competence, the component of curricular programmes of IGCSE school boards is better than ICSE board schools.

$\checkmark$ The quality assurance of Professional Competence, the component of curricular programmes of CBSE school boards is better than SSC board schools.

$\checkmark$ The quality assurance of Professional Competence, the component of curricular programmes of IGCSE school boards is better than CBSE board schools.

$\checkmark$ The quality assurance of Professional Competence, the component of curricular programmes of IGCSE school boards is better than SSC board schools.

Quality assurance of Teaching and Learning Process, the component of Curricular Programme

There is a significant difference in the quality assurance of Teaching and Learning Process, the component of Curricular Programme among secondary schools of different boards of Mumbai 
district. Since F value was found to be significant, each pair of means was then subjected to t-test and the following results were determined among the different pair of means.

$\checkmark$ The quality assurance of Teaching and Learning process, the component of curricular programmes of CBSE school boards is better than ICSE board schools.

$\checkmark$ The quality assurance of Teaching and Learning process, the component of curricular programmes of ICSE and SSC school boards is same.

$\checkmark$ The quality assurance of Teaching and Learning process, the component of curricular programmes of IGCSE school boards is better than ICSE board schools.

$\checkmark$ The quality assurance of Teaching and Learning process, the component of curricular programmes of CBSE school boards is better than SSC board schools.

$\checkmark$ The quality assurance of Teaching and Learning process, the component of curricular programmes of CBSE and IGCSE school boards is same.

$\checkmark$ The quality assurance of Teaching and Learning process, the component of curricular programmes of IGCSE school boards is better than SSC board schools.

\section{Quality assurance of Curricular Programme}

There is a significant difference in the quality assurance of Curricular Programme among secondary schools of different boards of Mumbai district. Since F value was found to be significant, each pair of means was then subjected to t-test and the following results were determined among the different pair of means.

$\checkmark$ The quality assurance of curricular programmes of CBSE school boards is better than ICSE board schools.

$\checkmark$ The quality assurance of curricular programmes of ICSE and SSC school boards is same.

$\checkmark$ The quality assurance of curricular programmes of IGCSE school boards is better than ICSE board schools.

$\checkmark$ The quality assurance of curricular programmes of CBSE school boards is better than SSC board schools.

$\checkmark$ The quality assurance of curricular programmes of CBSE and IGCSE school boards is same.

$\checkmark$ The quality assurance of curricular programmes of IGCSE school boards is better than SSC board schools.

From the above observations, it can be concluded that the perception of the teachers teaching in different educational boards indicate that in most comparisons it was IGCSE which was leading as compared to the other educational boards. Although there was an immense competition between CBSE and ICSE to bag the second level while comparing the boards in most of the components. It was noticed that both were almost equal in the number of times they stood second next to IGCSE. It was very evident from the study that in most of the components SSC was way behind than the other educational boards. Finally it was clearly indicated that quality assurance of curricular programme of different educational boards is in the following descending order, i.e, IGSCE, CBSE, ISCE and SSC. 


\section{References:}

Balani, B. (2015). School Effectiveness: A study of perceptions of secondary school teachers of different types of educational boards. Indian Journal of Applied Research, Vol 5 Issue 9.

Commission, Kothari. (1966). Report of the Education Commission. New Delhi: National Council of Educational Research and Training.

Covey, L. (1995). The Five Dimension DEnominator. 1995 ASQC Quality Management Conference.

Hislop, D. H. (May 2012). The Quality Assurance of Irsih Schools and the Role of Evaluation. Ireland: National University of Ireland.

Khaled Almadani, N. R. (2011). Quality Assurance: A pressing problem for Education in 21st Century. Problems of Education in 21st Century, Volume 32.

Leung, P.-1. (2001). Achieving quality education: a study of secondary school principals' and teachers' perception and strategiesfor promoting quality in their schools. Hong Kong: The University of Hong Kong (Pokfulam, Hong Kong).

School Council of India. (2007). Quality in School Education. New Delhi: Institute for Studies in Industrial Development.

UNICEF. (June 2000). Defining Quality In Education. New York, USA: Working Paper Series,UNCF.

Vakharia, R. (February 2012). A Study of Secondary School Students Response to Adversity in realtion to certain Psychological and performance factors. Mumbai: University of Mumbai. 